\title{
Modelling the coppice stand structure: an ecophysiological approach
}

\author{
G.E. Scarascia-Mugnozza, R. Valentini, E. Giordano \\ and A. Del Lungo
}

Institute of Forest Biology, University of Tuscia, 01100 Viterbo, Italy

\section{Introduction}

Limitations of water availability have serious impact on biomass production in mediterranean forest ecosystems. There is also growing evidence about the influence of water deficits on the development of insect or pathogen problems that eventually result in a general decline of these forests. Therefore, the analysis of the interactions between the water relations of a forest and its carbon cycle is of fundamental importance, in order to identify the most suitable silvicultural techniques to optimize productivity relative to water consumption (Jarvis, 1985).

A promising approach consists of the implementation of ecophysiological models that include the description of the structure of a forest stand together with the relationships between physiological processes and environmental parameters.

\section{Materials and Methods}

An experimental plot was established in a Quercus cerris $L$. forest stand, in central ltaly $\left(42^{\circ} 23^{\prime} \mathrm{N} ; 11^{\circ} 55^{\prime} \mathrm{E}\right)$. Its elevation is $150 \mathrm{~m}$ a.s.l. and the climate is mediterranean with a mean annual temperature of $17^{\circ} \mathrm{C}$, a mean annual precipitation of $900 \mathrm{~mm}$ and a marked summer drought. The stand is managed as a coppice with standards, with 2400 sprouts on about 1200 stumps/ha and with 96 standards/ha. The latter are trees, managed on a longer rotation than the coppice, to produce seeds for the regeneration of the stand. The rotation interval is $18 \mathrm{yr}$ for the coppice and a multiple of it for the standards. The mean annual aboveground biomass increment is 7 tons ha $a^{-1} \cdot \mathrm{yr}^{-1}$.

A detailed description of the canopy structure was accomplished by analyzing the crowns of 12 representative trees divided into 3 different diameter classes for the coppice $(4,10,17 \mathrm{~cm})$ and one for the standards $(25 \mathrm{~cm})$; these observations were made in September 1987, when the leaf area display was at its seasonal peak and the stand was at the end of the rotation. For each model tree, leaf area measured on representative branches was significantly and highly correlated $\left(R^{2}=0.70\right)$ to branch length. Using this regression and knowing the length, location and orientation of each first order branch, the vertical distribution of leaf area of each model tree was derived. The orientation (azimuth, midrib and lamina angles) of an appropriate sample of leaves was also measured, after stratification among trees and canopy layers (Isebrands and Michael, 1986).

Ecophysiological (stomatal conductance and plant water potentia!), climatic and soil moisture data were collected throughout 4 growing seasons in the same experimental plot, by means of a $20 \mathrm{~m}$ tall scaffold, an LI 1600 porometer, a 
PMS pressure chamber, a SOLO 20 neutron probe and various micrometeorological sensors.

\section{Results}

Large differences in total leaf area exist among model trees of different diameter classes: the smallest sprouts, of the $4 \mathrm{~cm}$ class, had an average total leaf area of $2.8 \mathrm{~m}^{2}$ per tree; the intermediate, $13.2 \mathrm{~m}^{2}$; the largest sprouts, $87.3 \mathrm{~m}^{2}$; and the average standard had a leaf area of $150.3 \mathrm{~m}^{2}$. Over the whole stand, standard leaf area represented approximately $50 \%$ of the leaf area displayed by the stand. The leaf area index (LAI) for the whole stand was 4.5, whereas for each average model tree, from the smallest sprout to the standard was, respectively, 0.3, 3.9, 3.3 and 3.5.
The vertical distribution of leaf area for the 4 average model trees was computed every $0.5 \mathrm{~m}$, taking into account the inclination and the length of the average branches for each layer (Fig. 1).

The results of leaf orientation measurements showed that leaves were non-randomly distributed, except for the azimuth angle that was uniformly distributed. The midrib and the lamina angles were normally distributed, according to the Kolmogorov-Smirnov test. Lamina angle was $88^{\circ} \pm 4.27$ for standards and coppice pooled together, indicating that the lamina were generally not tilted. The midrib angle was higher for the standards than for the coppice $\left(120^{\circ} \pm 6.39\right.$ vs $\left.93^{\circ} \pm 7.46\right)$ indicating that, in the former, leaves were generally inclined towards the ground, whereas in the coppice they were pointing upwards.

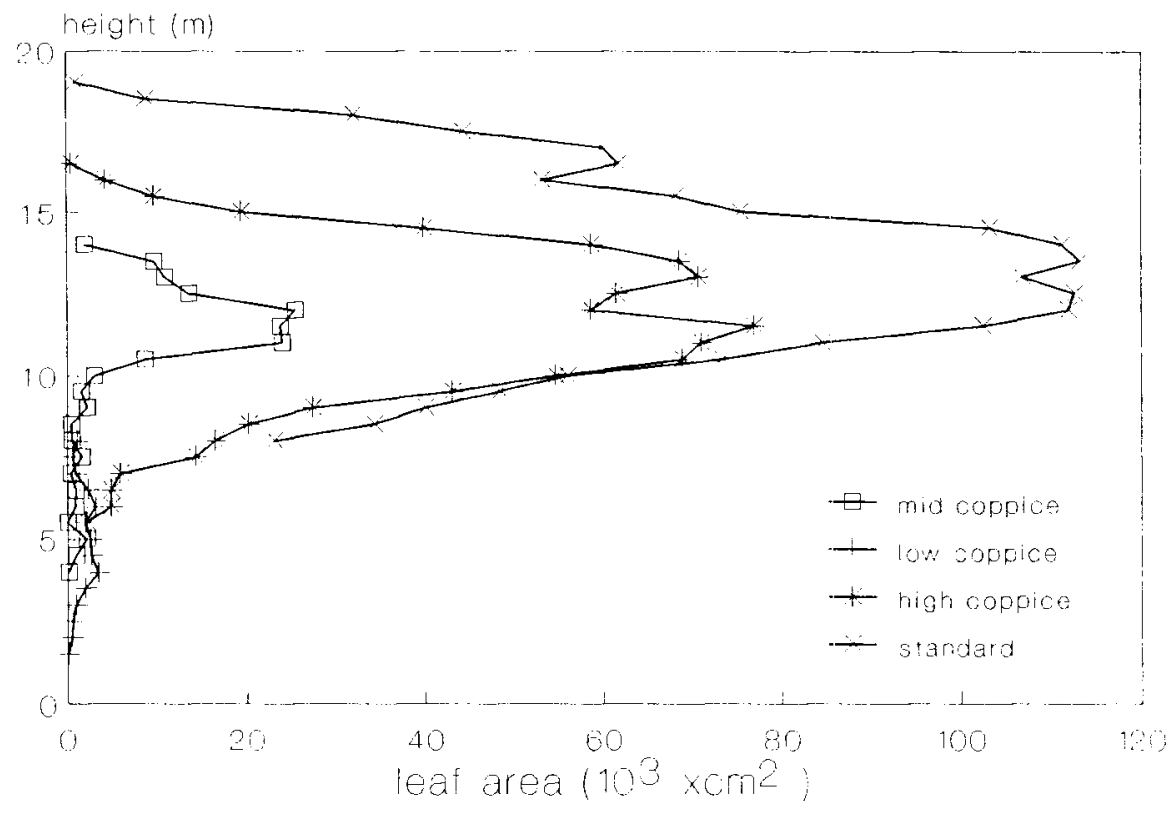

Fig. 1. Vertical distribution of leaf area in 4 model trees. 


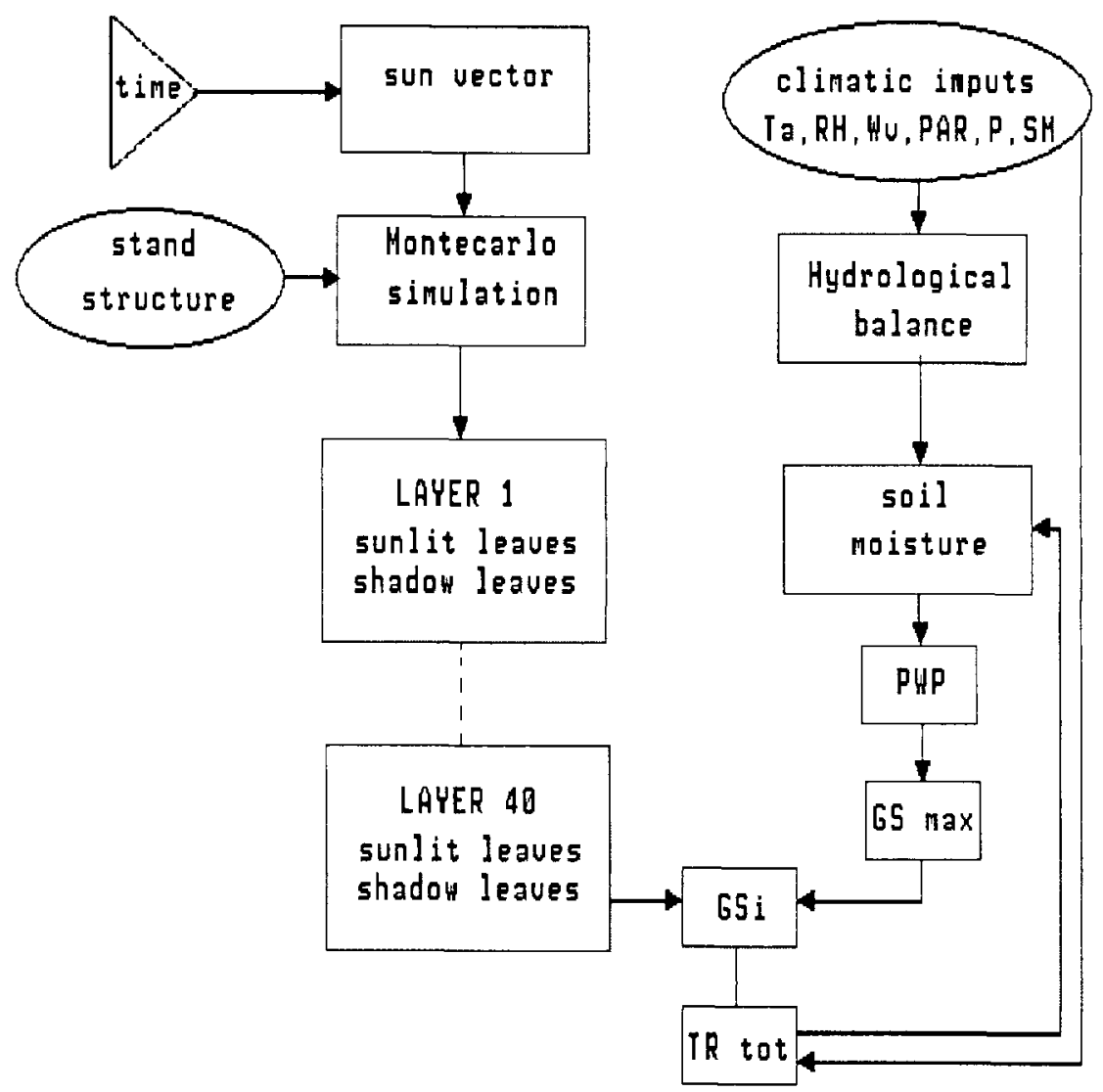

Fig. 2. Flow chart of the proposed ecophysiological model of light interception and water consumption. PWP $=$ predawn water potential; GS $\max =$ maximum stomatal conductance; GS $i=$ stomatal conductance of the $i$ th leaf; TR tot $=$ total daily transpiration.

The information about canopy structure and the response of physiological parameters to environmental conditions have been incorporated into a detailed ecophysiological model of light interception and water consumption by the forest stand (Fig. 2). The important components of the model consist of the subroutines describing light interception and stomatal conductance of the stand.

The former is based on a Montecarlo algorithm that simulates the characteristics of a population of $n$ leaves for each average model tree within each layer; the number $n$ is obviously related to the leaf area displayed by the tree at a given layer. For each leaf, the orientation is computed on the basis of the observed average and standard deviation values. Light interception is then estimated separately for the sunlit and the shade leaves; in the first case, the light level is computed according to the projection of the leaf on the plane perpendicular to solar radiation, whereas it is assumed that the shade leaves receive diffuse light that is extinguished according to Lambert-Beer's law. Stomatal conductance computation is based on its relation- 


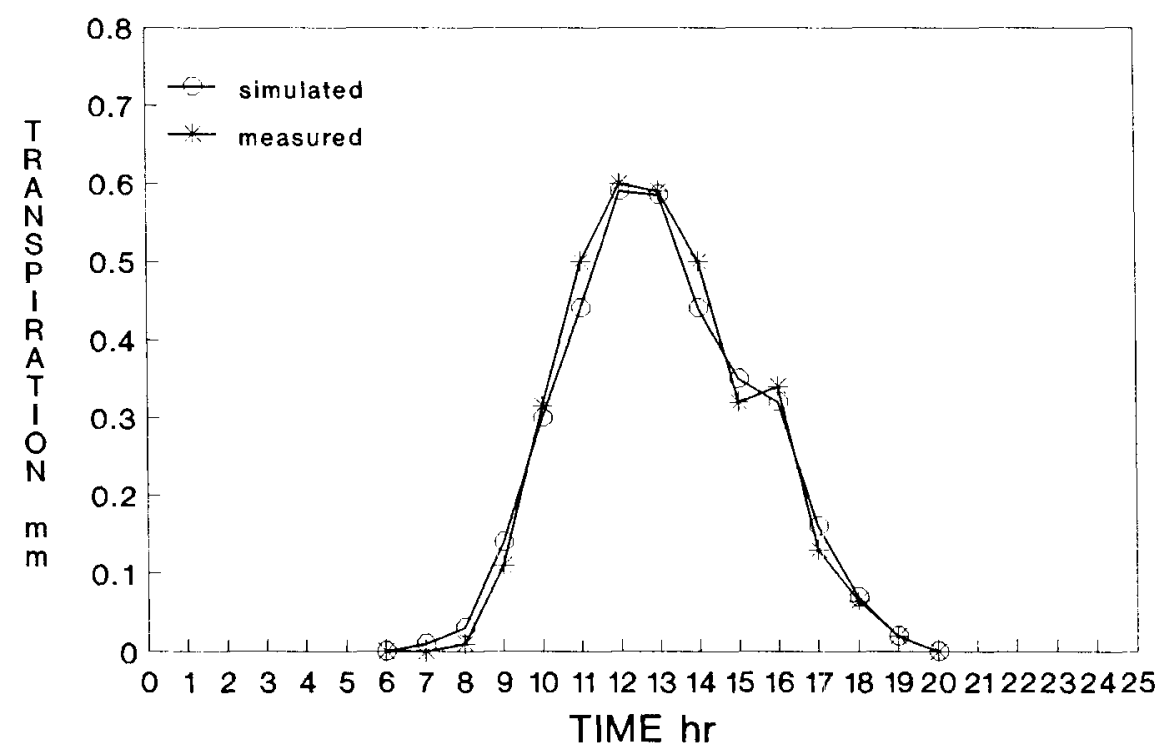

Fig. 3. Daily transpiration estimate for a clear sunny day.

ships with 2 ecophysiological parameters that have been found to be closely related to it: photosynthetic photon flux density $(P P F D)$ and predawn water potential of the trees $\left(P_{\mathrm{p}}\right)$ :

$$
g_{s}=\frac{a}{b+P_{\mathrm{p}}} \cdot \exp ^{-c P P F D^{-n}}
$$

\section{Discussion and Conclusions}

Detailed process-based models have much to offer for a better knowledge of forest ecosystem functioning and for their correct management (Landsberg, 1986). The model that we have implemented is based on a few fundamental physiological processes, such as light interception and stomatal conductance, as influenced by light regime and predawn water potential (Kaufmann, 1982). Transpirational results from the model showed close correspondence to values determined independently (Fig. 3).

\section{Acknowledgments}

Research work supported by CNR, italy. Special grant I.P.R.A. Sulsproject 1 Paper no. 2316.

\section{References}

Isebrands J.G. \& Michael D.A. (1986) Effects of leaf morphology and orientation on solar radiation interception and photosynthesis in Populus. In: Proc. Conf. Crown and Canopy Structure (Fujmori T. \& Whitehead D., eds.), Ibaraki, Japan, pp. 359-381

Jarvis P.G. (1985) Increasing productivity and value of temperate coniferous forest by manipulating site water balance. In: Weyerhaeuser Science Symp. Forest Potentials (Ballard R. \& Farnum P., eds.), Weyerhauser Co., Tacoma, pp. 39-74

Kaufmann M.R. (1982) Leaf conductance as a function of photosynthetic photon flux density and absolute humidity difference from leaf to air. Plant Physiol. 69, 1018-1022

Landsberg J.J. (1986) in: Physiological Ecology of Forest Production. Academic Press, New York, pp. 193 